printer exchange service. This system will probably be much used in the future by business firms. The new method enables letters, reports, and all kinds of messages to be type-written automatically between the offices of any two telephone subscribers, at any distance from one another. The typist in either office types the message, and it is printed simultaneously on the machine in the other's office. Both subscribers thus get a complete typed record of all the communications exchanged. The message can be sent at the speed at which the average typist works. To safeguard against wrong connexions, the sending subscriber presses the 'Who are you ?' key. The distant machine at once transmits back its own exchange and number. The service will be available in London in the spring and in the provinces in the summer. Speaking of the British Industries Fair, Sir Kingsley Wood said that at the Castle Bromwich Section the Post Office would have an exhibit which would be connected with Olympia in London, so that the public could see how the system operates. The Post Office is apparently following out its new policy of advertising. We think this highly advisable, as much ill-informed criticism has recently been directed at it.

\section{Pontifical Academy of Sciences.}

Ar the inaugural meeting of the eighty-fifth academic year of the Pontifical Academy of Sciences, on Dec. 20, it was reported that His Holiness Pope Pius XI., who was present at the meeting, had decided on the erection of a new hall in which the meetings could be held. After the delivery of the president's introductory address, in which the seientific activities of the past session were briefly reviewed, the awards of the assessors on the twelve papers on "Mendel's Law and Chromosomes ", submitted in competition for a prize of 10,000 lire, were announced. First place has been accorded to Prof. Paolo Enriquez, of the University of Padua, while the paper of Dr. Fraser Darling, of Edinburgh, and that of Prof. Carlo Jucci are considered worthy of special mention, and are to be published at the expense of the Academy.

A Number of communications were then presented to the meeting of the Pontifical Academy. In a paper on so-called embryos of a foraminifer, E. Dervieux stated that organic remains similar to those described by Prof. De Lapparent in 1925 as embryos of Logena have now been found in a deposit dredged from a depth of more than 2000 metres near the Balearic Islands. Inertia of space was discussed by G. Gianfranceschi, and a new Sicilian species of the genus Amphimallus Latr. was described by P. Luigioni. Dealing with the subject of physical space, matter, and electrons, P. Giorgi expressed the view that the equations of the new physics have reconciled the photonic and undulatory conceptions, but are not yet definitive, as they take account neither of the equality of all electrons or of all protons, nor of the difference in mass between electrons and protons, and, moreover, do not seem adequately to interpret nuclear physics. An account is given by Neviani of the skeleton of Globicephalus milas found some years ago near Ladispeli.
In a note by G. Strein on the total lunar eclipse of Sept. 26-observed under ideal conditions at the Vatican Observatory - it is stated that the most striking feature was the appearance of the blueish luminous erescent, which showed no appreciable asymmetry with regard to the straight line joining the centre of the moon with that of the shadow. This phenomenon was also examined by $M$. Ananoff and referred to in Nature of Jan.23, p. 136. A paper entitled "Independence of Histogenesis and Organogenesis", by S. Ranzi, records interesting results connected with the development of pieces of the embryo of Sepia. The rock samples and fossils collected by General Nobile in Franz Joseph Land were discussed by G. De Angelis d'Ossat, and the various radiations influencing vegetable tumours were classified by Vincenzo Rivera into those which enhance and those which depress the growth of such tumours. Other communications dealt with the occurrence of Orbitolina in North America (A. Silvestri), Insecta orientalia (L. Navàs), the proteases of the acido-proteolytes (C. Gorini), the study of equations by an extension of Abel's problem (Scatizizi), etc.

\section{British Museum Acquisitions.}

Among recent acquisitions by the Zoological Department of the British Museum (Natural History) are three Norwegian beavers and a specimen of the rare squid Stenoteuthis caroli, about $6.5 \mathrm{ft}$. long, stranded at Scarborough. It is interesting to find that the Norwegian beaver is still holding its own. A high percentage of the squids stranded in Great Britain are found on the Yorkshire coast. The Department of Geology has recently been enriched by the presentation, through the trustees of the Vernay-Archbold Expedition, of a large series of fossils collected by Dr. Errol I. White in Madagascar during 1929. The specimens are chiefly those of the sub-fossil fauna which became extinct probably within historic times, for mention of many of the creatures, some of which are remarkable for their great size, occurs in Malagasy folk-tales. Among the interesting specimens are the remains of the extinct Giant Lemur, Megaladapis, which has the largest skull of any known primate, and is peculiar in lacking the front cutting-teeth (incisors) in the upper jaw. A fragment weighing $1084 \mathrm{gm}$. of the rare pallasite type of meteorite of a new find near Alice Springs, MacDonnell Ranges, Central Aus tralia, and various minerals and rocks collected by the donor have been presented by Dr. Herbert Basedow to the Department of Minerals. A large collection of co-types of Chinese species of Rhododendron have been presented by the Edinburgh Botanic Garden. These were from collections made by the late Mr. George Forrest, news of whose death in Yunnan reached England only a few days ago. Miss M. Brown has presented the British herbarium of her father, Henry Brown (1824-92). The herbarium was got together mainly while Henry Brown was a pupil of Isaac Brown, of Hitchin, who was a well-known naturalist and Lord Lister's first schoolmaster. 